\title{
ANALISIS DATA RESISTIVITAS DAN POLARISASI TERIMBAS GUNA MENDETEKSI KEBERADAAN MINERALISASI DAERAH KARANGSAMBUNG
}

RESISTIVITY AND INDUCED POLARIZATION DATA

ANALYSIS FOR DETECTING THE EXISTENCE OF MINERALIZATION AT KARANGSAMBUNG AREA

\author{
Putri Pertiwi $^{1^{*}}$, Tito Waluyo Jiwandono ${ }^{2}$ \\ 1,2Program Studi Teknik Geofisika, Fakultas Teknologi M ineral, U niversitas Pembangunan N asional \\ V eteran Y ogyakarta
}

Received: 2020 , October $22^{\text {nd }}$ Accepted: 2021, $M$ arch $7^{\text {th }}$

\section{Keyword:}

Chargeability;

Induced polaritation;

Karangsambung;

Mineralization;

Resistivity.

\section{Corespondent Email:}

115150049@student.upnyk.ac.id

\section{H ow to cite this article:}

Pertiwi, P. \& Jiwandono, T.W.

\begin{abstract}
Abstrak. Karangsambung merupakan salah satu tempat tersingkapnya batuan campuran yaitu Komplek Melange Lok Ulo yang berumur Kapur akhir hingga Paleosen. Aktivitas vulkanik dan tektonik pada daerah Karangsambung mengakibatkan tersingkapnya intrusi batuan beku diabas dengan struktur columnar joint. Penelitian ini bertujuan untuk mengindikasi keberadaan mineralisasi yang disebabkan fluida hidrotermal sebagai produk sisa proses magmatisme. Fluida hidrotermal menerobos batuan samping, kemudian melewati celah-celah batuan yang telah ada akibat berkembangnya struktur geologi. Penelitian ini memanfaatkan dua metode geofisika berupa metode resistivitas dan polarisasi terimbas dengan konfigurasi dipoledipole. $M$ etode resistivitas digunakan untuk mendeteksi persebaran litologi batuan, sedangkan polarisasi terimbas digunakan untuk mendeteksi adanya mineral ubahan penciri alterasi bertipe sulfida seperti pirit, serisit dan sebagainya. Pengukuran dilakukan sebanyak 5 lintasan dengan panjang setiap lintasan 200 meter. Pengolahan data menggunakan RES2DINV, M apinfo Discover 3D, dan Rockworks15. Analisis penampang resistivitas dan polarisasi terimbas mengindikasikan adanya mineralisasi ditunjukan dengan nilai resistivitas yang tinggi yaitu $>700 \Omega \mathrm{m}$ dan nilai chargeabilitas yang tinggi yaitu $>300 \mathrm{~ms}$. Area tersebut diduga kuat sebagai pengaruh dari proses silisifikasi atau pengayaan silika, serta terdapat beberapa indikasi yang menunjukan pengaruh dari propilitik. Analisis dari korelasi semua penampang polarisasi terimbas pemodelan 3D menunjukkan bahwa mineralisasi berorientasi dari arah utara-selatan serta volume zona mineralisasi diperkirakan sebesar 70.500
\end{abstract}


(2021). Analisis Data

Resistivitas dan Polaritas

Terimbas Guna M endeteksi

Keberadaan M ineralisasi

Daerah Karangsambung,

Kebumen, Jawa Tengah. Jurnal

Geofisika Eksplorasi, 07(01), 71-

83.

(c) 2021 JGE (Jurnal Geofisika

Eksplorasi). This article is an open access article distributed under the terms and conditions of the Creative Commons Attribution (CC BY NC) $\mathrm{m}^{3}$.

\begin{abstract}
Karangsambung is one of the places where mixed rock is exposed that is lok ulo mélange complex which is the late cretaceous up to the paleocene. Volcanic and tectonic activity in the Karangsambung area results exposure of diabase igneous rock intrusion with a columnar joint structure. The purpose of this research to indicate the potential of mineralization caused by hydrothermal fluid as a residual product of a magmatism process. The hydrothermal fluid will break through the side rocks, then through the gaps that have been caused by the development of geological structures. This research utilizes two geophysical methods in the form of resistivity and induced polarization with dipole-dipole configuration. Resistivity method used to detect the distribution of rock lithology, while induced polarization used to detect the presence alteration mineral identifier of type sulfide alterations such us pyrite, sericite and so on. M easurements were taken as many as 5 lines with a length of each line is 200 meters. Processing data using RES2DINV, Mapinfo Discover 3D, and Rockworks15. The analysis of resistivity and induced polarization cross-section indicated the presence of mineralization is shown with a high resistivity value is $>700 \Omega \mathrm{m}$ and a high chargeability value also $>300 \mathrm{~ms}$. The area is strongly suspected as the effect of silicification or enrichment of silica, and there are severals indication that indicate the presence of propylitics. Analysis of the correlations all induced polarization sections and 3D modelling identified that mineralization is oriented from the north-south direction and volume of mineralization zone of $70.500 \mathrm{~m}^{3}$.
\end{abstract}

\section{PENDAHULUAN}

Karangsambung merupakan salah satu tempat tersingkapnya batuan campuran, yaitu Komplek Melange Lok Ulo yang berumur Kapur Akhir hingga Paleosen. Aktivitas vulkanik dan tektonik pada daerah Karangsambung mengakibatkan tersingkapnya intrusi batuan beku diabas dengan struktur columnar joint.

Indikasi keterdapatan mineralisasi disebabkan oleh fluida hidrotermal sebagai produk sisa dari sebuah proses magmatisme. Fluida hidrotermal akan menerobos batuan samping, kemudian melewati celah-celah batuan yang telah ada akibat berkembangnya struktur geologi.

Potensi adanya mineralisasi pada daerah penelitian telah dilakukan sebelumnya oleh Puswanto dan Ansori (2011) dengan mengamati karateristik urat kuarsa pada batuan yang teralterasi. Penelitian tersebut menyimpulkan bahwa vein masif dan stockwork merupakan tipe urat kuarsa yang berkembang di daerah Karangsambung. Hal tersebut ditunjukkan juga oleh struktur kuarsa (sebagian kalsedonik), tekstur tumbuh, pengisian rongga-rongga (comb), berukuran halus (sebagian terbreksiasi), dan sedikit mengandung pirit dan sfalerit.

Menurut Puswanto dan Ansori (2011) pada Mei 1997, pernah dilakukannya suatu penelitian hasil kolaborasi antara PT Antam Tbk dan American Celtic Mineral Ltd di hulu Sungai Bengkok, yang menjelaskan bahwa di daerah ini memiliki tipe sistem mineralisasi epitermal sulfida tinggi, dengan anomali AuAgrendah.

Studi kali ini memanfaatkan beberapa sifat fisik batuan diantaranya resistivitas dan chargeabilitas. Adanya kontras sifat fisik 
seperti resistivitas dan chargeabilitas pada batuan teralterasi terhadap batuan asalnya memungkinkan dilakukan survei geofisika melalui beberapa metode, seperti resistivitas (Srigutomo dkk., 2016) dan polarisasi terimbas (Dakir dkk., 2019; M ostafaei \& Ramazi, 2019; Zhdanov dkk., 2018; Ali dkk., 2020).

Dengan mengintegrasikan metode tersebut diharapkan tujuan dari penelitian ini dapat tercapai yaitu:

a. M enginterpretasi keberadaan endapan mineral yang berasosiasi dengan batuan teralterasi berdasarkan nilai resistivitas dan polarisasi terimbas.

b. Mengindentifikasi lokasi dan potensi arah persebaran suatu endapan mineral berdasarkan korelasi penampang.

c. Mendapatkan volume serta sebaran zona mineralisasi berdasarkan pemodelan 3D chargeabilitas.

\section{TINJAUAN PUSTAKA}

\subsection{Geologi}

\subsubsection{Stratigrafi}

Komplek Lok Ulo ditafsirkan merupakan sebuah batuan bancuh (melange) berumur Pra-Tersier dan Tersier Awal yang tercampur aduk pada masa dasar batulempung yang diduga sebagai batuan tertua di daerah ini. Selanjutnya terendapkan Formasi Karangsambung berumur Eosen Tengah sampai Oligosen terendapkan diatasnya.

Proses pengendapan berlangsung hingga umur Oligosen sampai Miosen Awal yang terendapkan selaras dengan Formasi Karangsambung, yaitu Formasi Totogan. Kemudian terendapkannya Formasi Waturanda pada Miosen Awal sebagai endapan turbidit. Setelah itu, pada umur Miosen Tengah diendapkan Formasi Penosogoan dan Formasi Halang. Pada umur Akhir Miosen Tengah sampai Pliosen A wal, serangkaian endapan sedimen turbidit terbentuk dengan tipe breksi. Endapan gunung api muda berumur Kwarter diendapkan tak selaras pada Komplek Lok Ulo yang dijumpai di sudut timur laut lembar (Gambar 1).

Endapan alluvium dan pantai merupakan sedimen paling muda yang terendapkan tak selaras ke satuan batuan yang lebih tua. Diabas merupakan batuan beku terobosan berumur A khir M iosen Tengah yang dijumpai di daerah ini, berupa hasil retas lempeng (Asikin dkk., 1992).

\subsubsection{Alterasi Hidrotermal dan Mineralisasi}

Fluida hidrotermal secara kimia akan berinteraksi terhadap mineral pada batuan dan menyebabkan terbentuknya himpunan mineral baru yang sesuai dengan kondisi lingkungan yang terbentuk. Corbett dan Leach (1998) berpendapat bahwa mineral alterasi yang terbentuk di suatu lokasi sangat dipengaruhi oleh tujuh faktor utama yaitu suhu, kimiawi fluida, konsentrasi fluida, komposisi batuan dinding, kinetik, durasi dan tingkat ekuilibrium, dan permeabilitas.

Corbett dan Leach (1998) menyatakan bahwa zona alterasi yang berasosiasi dengan endapan bijih dapat dibagi menjadi lima zona utama berdasarkan himpunan mineral yang terbentuk antara lain zona potasik, filik, argilik lanjut, argilik, dan propolitik.

Menurut Gary dkk. (1972), mineralisasi adalah suatu proses introduksi atau masuknya mineral ke dalam batuan yang kemudian membentuk mineral bijih dan mineral penyertanya (gangue) sehingga terbentuk endapan mineral.

Puswanto dan Ansori (2011) dalam penilitiannya menjelaskan bahwa, anggota Formasi Kompleks Lok Ulo seperti basal, gabro, dan filit merupakan hasil mineralisasi yang berkembang di daerah penelitian. Zona alterasi silisifikasi yang berasosiasi dengan mineralisasi sulfida pirit-sfalerit dan urat-urat kuarsa pengisi rekahan merupakan produk alterasi hidrotermal berupa alterasi propilitik. Batuan yang terubah akan mengubah nilai massa jenis batuan asal. M enurut Irvine dan 
Smith (1990), proses alterasi hidrothermal silisifikasi dapat meningkatakan massa jenis batuan pada batuan vulkanik yang poros. Kebalikannya, altrasi hidrotermal akan menurunkan densitas pada batuan, karena meningkatkan volume rekahan, pelarutan dan proses leaching.

\subsubsection{Emas}

Emas merupakan logam yang memiliki

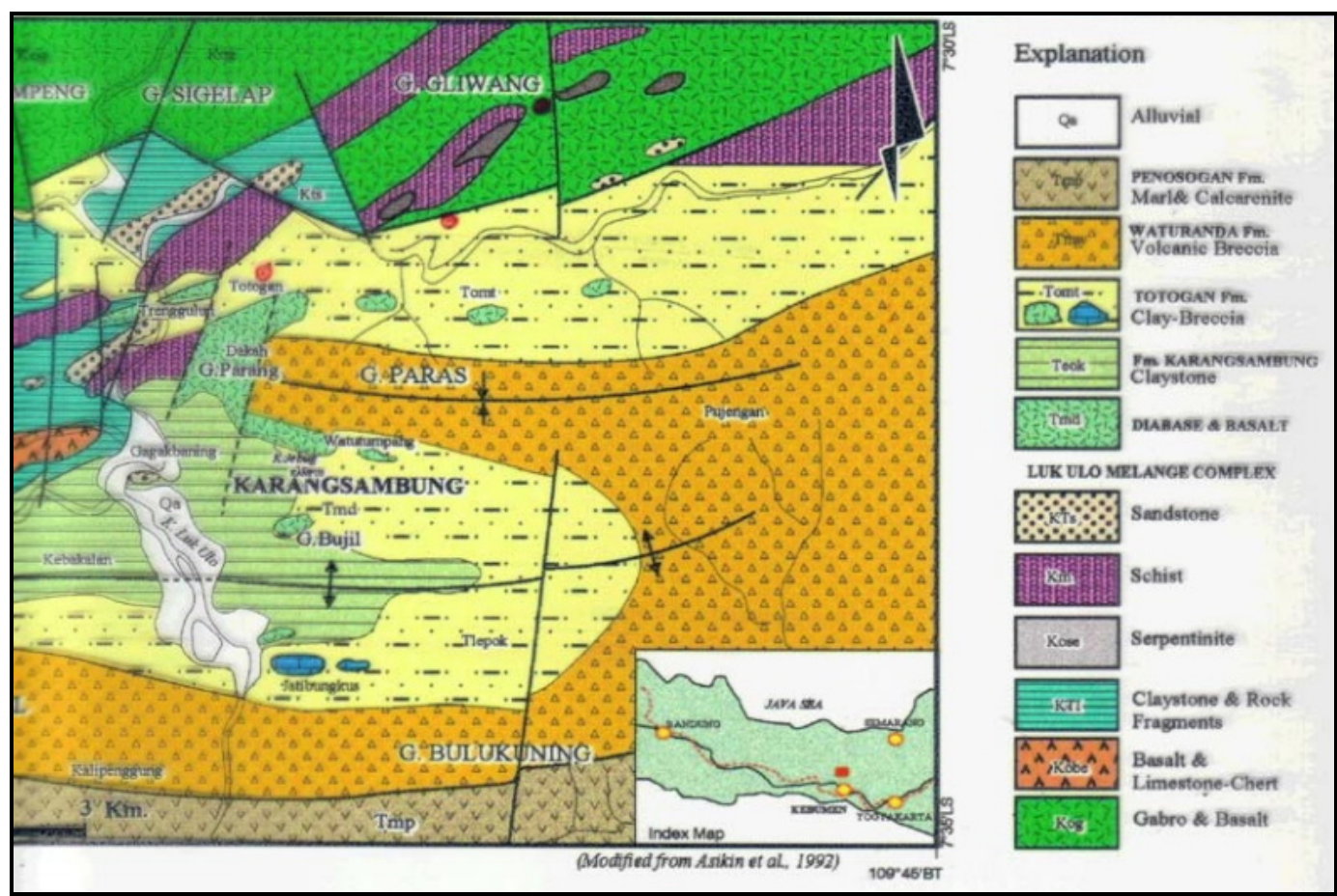

Gambar 1. Peta geologi regional lembar Karangsambung (Noor, 2009) modifikasi Asikin dkk. (1992).

derajat kekerasan sekitar 2.5-3 (skala Mohs) dan bersifat lunak (mudah ditempa), dengan berat jenis tergantung pada jenis kandungan logam lain yang berasosiasi dengannya. Genesa emas terbagi dua yaitu endapan primer dan endapan letakan (placer).

Endapan primer ditemukan dalam bentuk logam (native) yang terdapat di dalam retakanretakan batuan kuarsa dan dalam bentuk mineral yang terbentuk dari proses magmatisme dan vulkanisme. Sebagian terbentuk karena proses metasomatisme kontak dan larutan hidrotermal.

Sedangkan endapan letakan (placer) ditemukan dalam bentuk alluvial karena proses pelapukan terhadap batuan-batuan yang mengandung emas atau sebagai hasil pergerakan endapan primer. Sebagian besar ditemukan secara bersamaan dengan mineral lainnya seperti silikat, perak, platina, pirit dan lainnnya (Lucas, 1985).

\subsection{M etode Geolistrik}

\subsubsection{TDIP (Time Domain Induced Polarization)}

Injeksi arus listrik yang dilakukan pada survei IP pada dasarnya akan menghasilkan nilai potensial total $\left(\mathrm{V}_{0}\right)$ yang terdiri atas potensial arus injeksi (V) dan potensial polarisasi $\left(V_{p}\right)$. Injeksi arus listrik yang dimatikan akan menyebabkan potensial jatuh secara langsung dengan nilai sebesar $\mathrm{V}$ dan hanya menyisakan $\mathrm{Vp}$ yang kemudian meluruh dalam fungsi waktu.

Nilai IP yang ditimbulkan akibat injeksi arus listrik dapat diukur dengan cara membagi 
nilai potensial polarisasi $\left(\mathrm{V}_{\mathrm{p}}\right)$ terhadap nilai potensial totalnya $\left(\mathrm{V}_{0}\right)$ dan biasanya dinyatakan dalam unit millivolt per volt ataupun persen. Nilai chargeabilitas semu diperoleh dengan cara menghitung luas area secara diskrit ataupun keseluruhan pada area di bawah kurva peluruhan dalam rentang waktu $t_{1}$ dan $t_{2}$, kemudian membaginya dengan nilai potensial total $\left(\mathrm{V}_{0}\right)$.

$$
M_{a}=\frac{1}{v_{0}} \int_{t_{1}}^{t_{2}} V_{p}(t) d t=\frac{A}{V_{0}}
$$

dengan,

$M_{a} \quad$ : Chargeabilitas semu (ms)

$\mathrm{V}_{0} \quad$ : Potensial total (volt)

$\mathrm{t}_{1}, \mathrm{t}_{2}$ : Batas waktu integrasi (ms)

$\mathrm{V}_{\mathrm{p}}(\mathrm{t})$ : Potensial pada waktu $\mathrm{t}$ (volt)

\subsubsection{M etode Resistivitas}

M etode resistivitas adalah salah satu dari metode geolistrik yang digunakan untuk menyelidiki struktur bawah permukaan berdasarkan perbedaan resistivitas batuan. Teori dasar dari metode resistivitas adalah Hukum Ohm, yaitu hubungan antara arus yang dialirkan dan beda potensial yang terukur (Telford dkk., 1976). Hubungannya adalah sebagai berikut:

$$
V=I \times R
$$

dengan,

$\mathrm{R}$ : Tahanan (ohm.meter atau $\Omega \mathrm{m}$ )

$\mathrm{V}$ : Tegangan (millivolt atau $\mathrm{mV}$ )

$\mathrm{I}$ : Kuat arus (miliampere atau $\mathrm{mA}$ )

\subsubsection{Konfigurasi Dipole-dipole}

Konfigurasi dipole-dipole pada prinsipnya mengggunakan 4 buah elektroda yaitu sepasang elektroda arus (current dipole $A B$ ) dan sepasang elektroda potensial (potential dipole (D). Elektroda arus dan elektroda potensial bisa terletak tidak segaris dan tidak simetris seperti pada Gambar 2 (Lowrie, 2007).

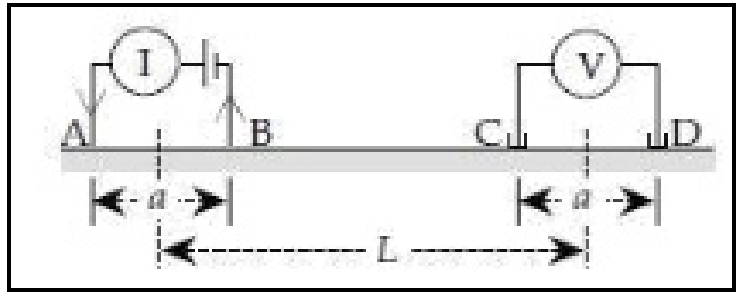

Gambar 2. Konfigurasi Dipoledipole (Lowrie, 2007).

\section{METODE PENELITIAN}

\subsection{Pengambilan Data}

A kuisisi data pada survei metode resistivitas dan polarisasi terimbas di daerah Karangsambung (Gambar 3) dilakukan pada 5 lintasan dengan panjang bentangan masingmasing 200 meter dan spasi antar elektroda sebesar 10 meter (Gambar 4). Konfigurasi elektroda yang dipilih dalam penelitian ini adalah dipole-dipole.

Lintasan metode polarisasi terimbas dibuat dengan orientasi barat-timur sama dengan tujuan untuk memotong struktur yang diduga menjadi tempat pengendapan mineral. A kuisisi pada metode geolistrik menggunakan instrumen berjenis Syscal Junior dengan komponen pendukung berupa kabel, sumber listrik (aki $12 \mathrm{~V}$ olt), elektroda, dan porous pot.

\subsection{Pengolahan Data}

Tahap pengolahan data pada metode geolistrik (Gambar 5), diawali dengan melakukan quality control (QC) yang bertujuan untuk menghilangkan data dengan kualitas yang buruk (bad datum point). Data IP yang telah melalui tahap QC kemudian masuk pada proses inversi yang dilakukan untuk mendapatkan nilai resistivitas dan chargeabilitas sebenarnya.

Proses inversi dilakukan pada perangkat lunak RES2DINV menggunakan least square inversion. Penampang resistivitas dan charge- 
abilitas hasil inversi kemudian diolah lebih lanjut untuk memperoleh model kemenerusan zona mineralisasi. Pembuatan model kemenerusan zona mineralisasi dilakukan menggunakan perangkat lunak Maplnfo Discover 3D. Proses untuk mengetahui potensi keberadaan zona mineralisasi digunakan perangkat lunak Rockworks15 dengan menghitung volume berdasarkan cut off dari parameter nilai chargeabilitas sebelumnya.

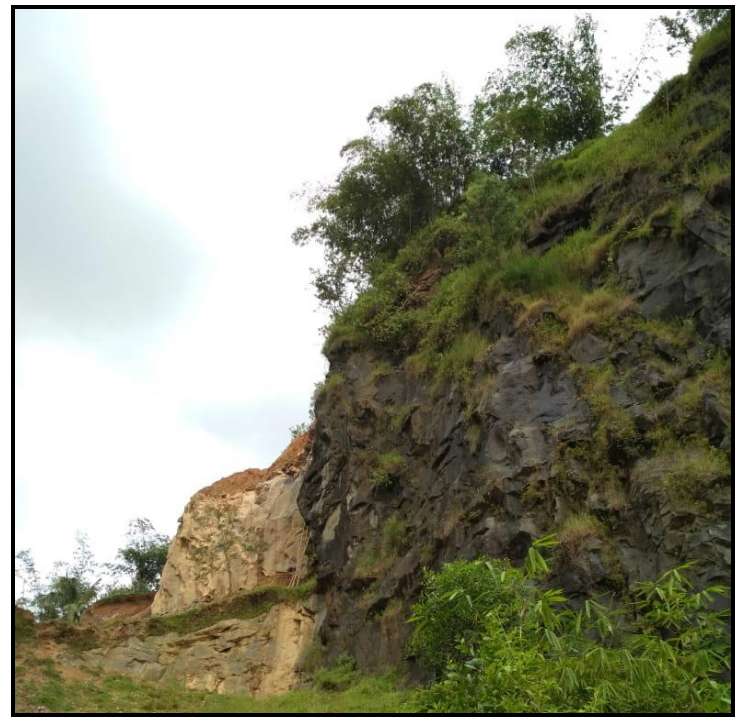

Gambar 3. Lokasi akuisisi data pada daerah Karangsambung (singkapan tebing).

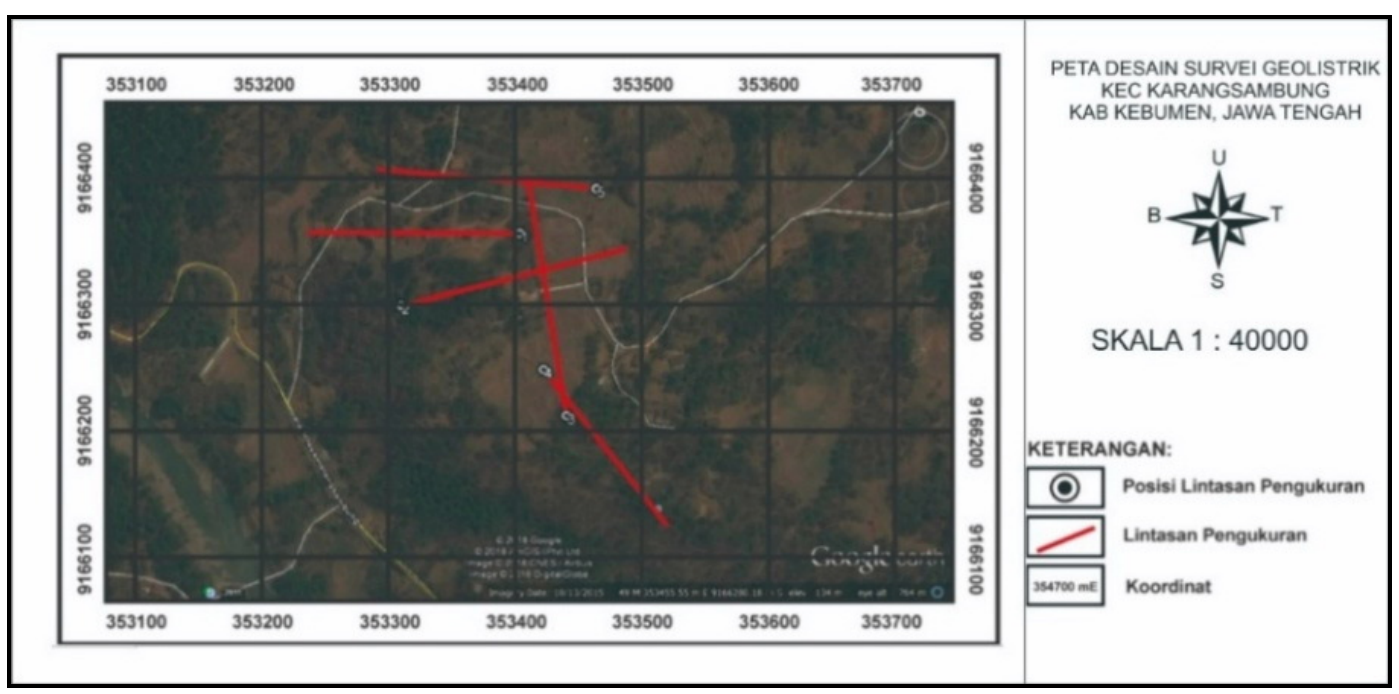

Gambar 4. Desain survei. 


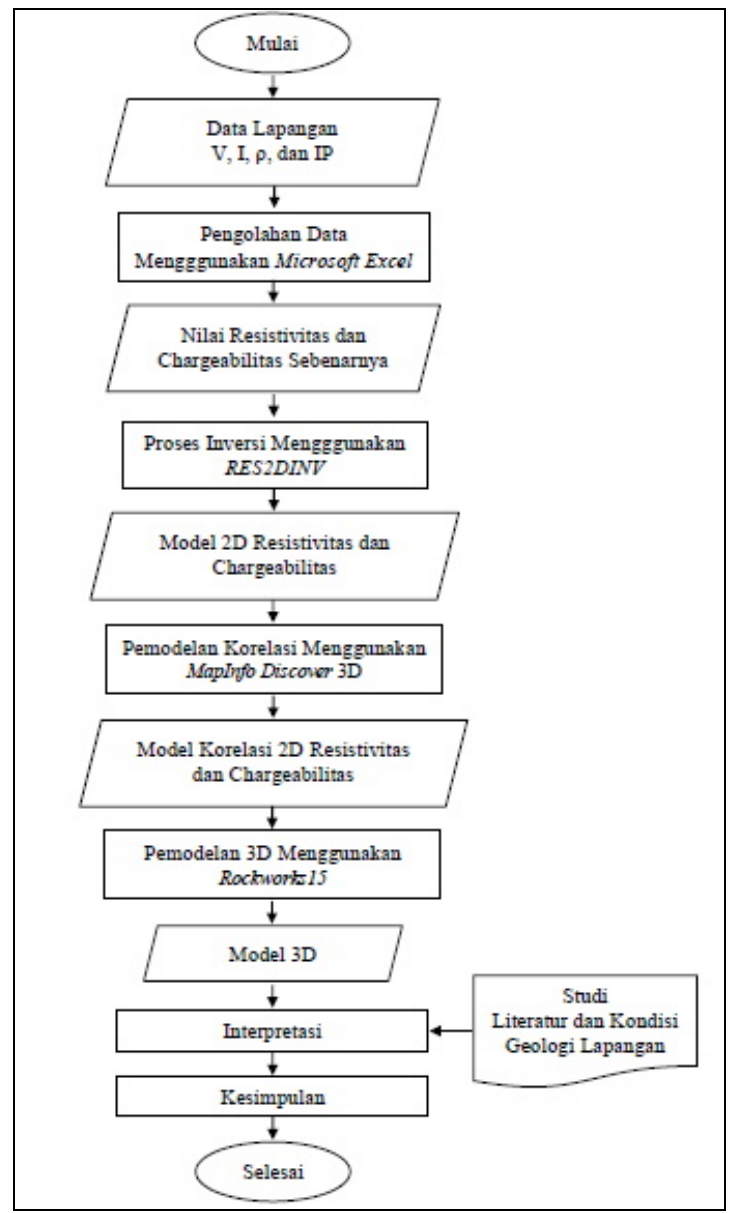

Gambar 5. Diagram alir pengolahan.

\section{HASIL DAN PEMBAHASAN}

Berdasarkan Tabel $\mathbf{1}$ dan $\mathbf{2}$ yang mengacu berdasarkan Reynold (2011) maka nilai resistivitas dan chargeabilitas dapat diinterpretasikan sebagai berikut:

a. Soil atau lapisan jenuh air mepunyai nilai resistivitas 0-100 $\Omega \mathrm{m}$ dan chargeabilitas 0 $100 \mathrm{~ms}$.

b. Batuan beku diabas mempunyai nilai resistivitas $>700 \Omega \mathrm{m}$ dan chargeabilitas 0 $100 \mathrm{~ms}$.

c. Zona alterasi propilitik mempunyai nilai resistivitas $>700 \Omega \mathrm{m}$ dan chargeabilitas 100-300 ms.

d. Zona mineralisasi Au pada propilitik mempunyai nilai resistivitas 0-700 $\Omega \mathrm{m}$ dan chargeabilitas $\geq 100 \mathrm{~ms}$. e. Zona mineralisasi Au pada silika memiliki nilai resistivitas $>700 \Omega \mathrm{m}$ dan chargeabilitas $>300 \mathrm{~ms}$.

Tabel 1. Klasifikasi nilai resistivitas dan chargeabilitas.

\begin{tabular}{ccc}
\hline Skala & $\begin{array}{c}\text { Resistivitas } \\
(\Omega \mathrm{m})\end{array}$ & $\begin{array}{c}\text { Chargeabilitas } \\
(\mathrm{ms})\end{array}$ \\
\hline Rendah & $0-100$ & $0-100$ \\
Sedang & $100-700$ & $100-300$ \\
Tinggi & $>700$ & $>300$
\end{tabular}

Tabel 2. Interpretasi berdasarkan nilai resistivitas dan chargeabilitas.

\begin{tabular}{ccc}
\hline $\begin{array}{c}\text { Resistivitas } \\
(\Omega \mathrm{m})\end{array}$ & $\begin{array}{c}\text { Chargeabilitas } \\
(\mathrm{ms})\end{array}$ & Interpretasi \\
\hline Rendah & Rendah & $\begin{array}{c}\text { Soil/Lapisan } \\
\text { jenuh air } \\
\text { Batuan beku }\end{array}$
\end{tabular}




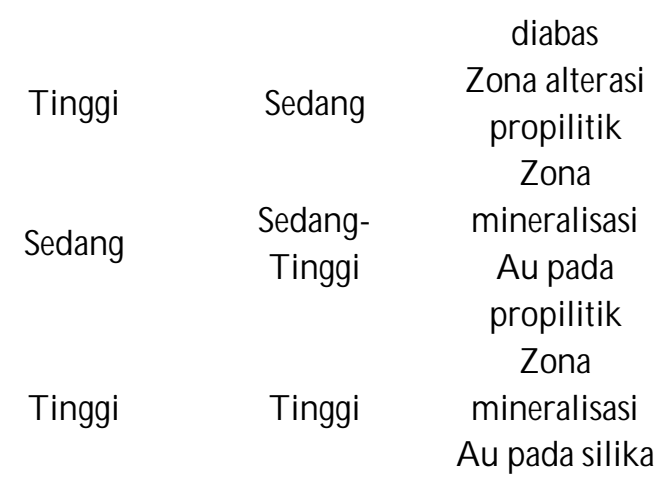

Berdasarkan penampang 2D resistivitas dan chageabilitas pada lintasan 1 (Gambar 6) respon keberadaan zona mineralisasi dapat terlihat pada panjang lintasan 35-55 meter dengan elevasi 135-145 meter serta pada panjang lintasan 115-120 meter dengan elevasi
132.5-137.5 meter dimana zona mineralisasi tersebut berasosiasi pada silika berupa zona urat kuarsa yang berkembang seperti vein dengan menunjukkan adanya struktur (kekar).

Hasil analisis stereografis dari Puswanto dan Ansori (2011) menunjukkan bahwa secara umum bidang sesar ini mengindikasikan sesar turun berarah timurlaut-baratdaya (NE-SW) dan mempunyai arah $\sigma 1$ vertikal $N 60^{\circ} \mathrm{E}, \sigma 2$ $\mathrm{N} 222^{\circ} \mathrm{E}, \sigma 3 \mathrm{~N} 314^{\circ} \mathrm{E}$, kemiringan bidang sesar besar $45^{\circ}-90^{\circ}$ dan sudut geser sesar $>45^{\circ}$. Zona tersebut ditunjukkan dengan nilai resistivitas dan chargeabilitas yang tinggi yaitu $>700 \Omega \mathrm{m}$ dan $>300 \mathrm{~ms}$.

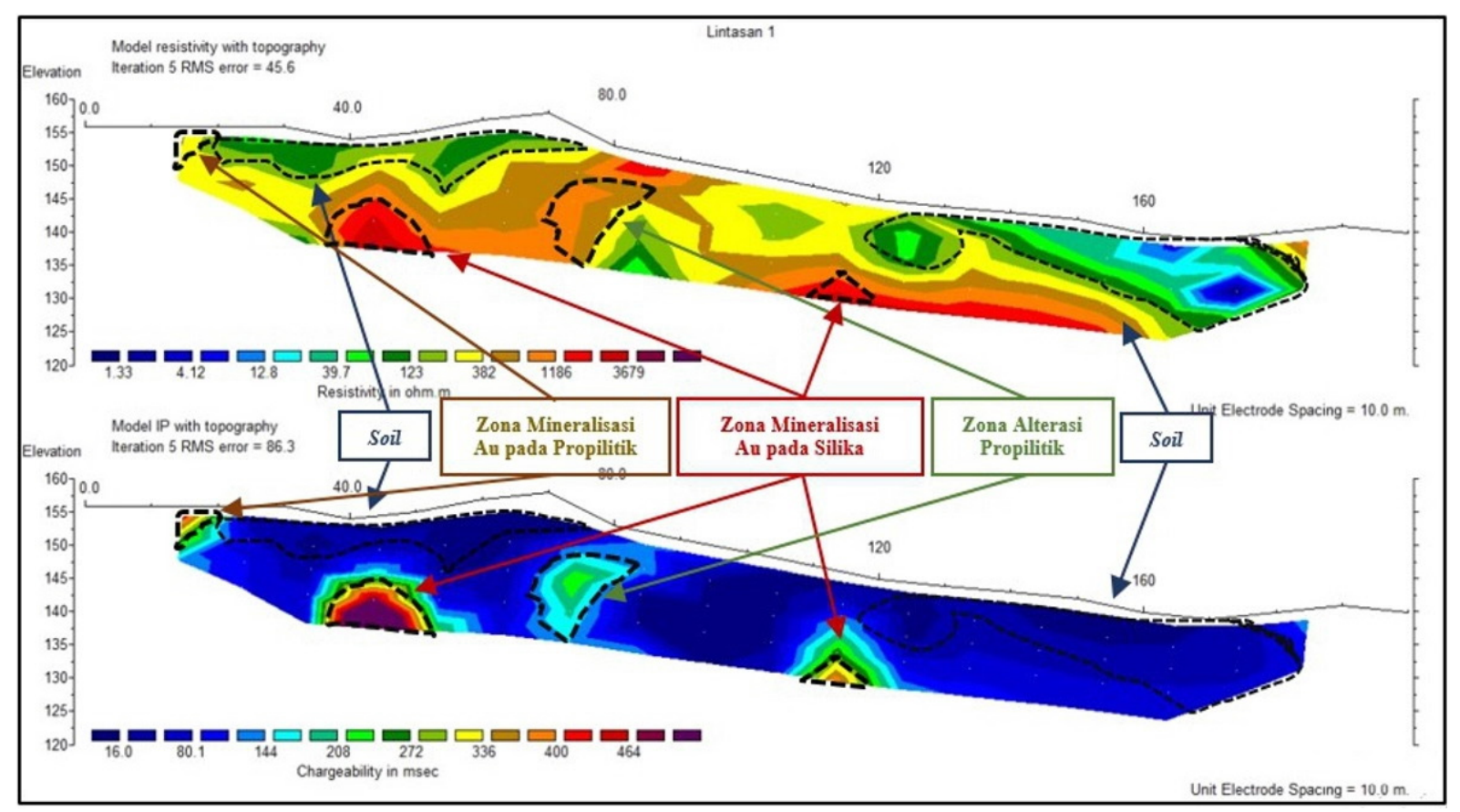

Gambar 6. Penampang resistivitas dan chargeabilitas lintasan 1. 


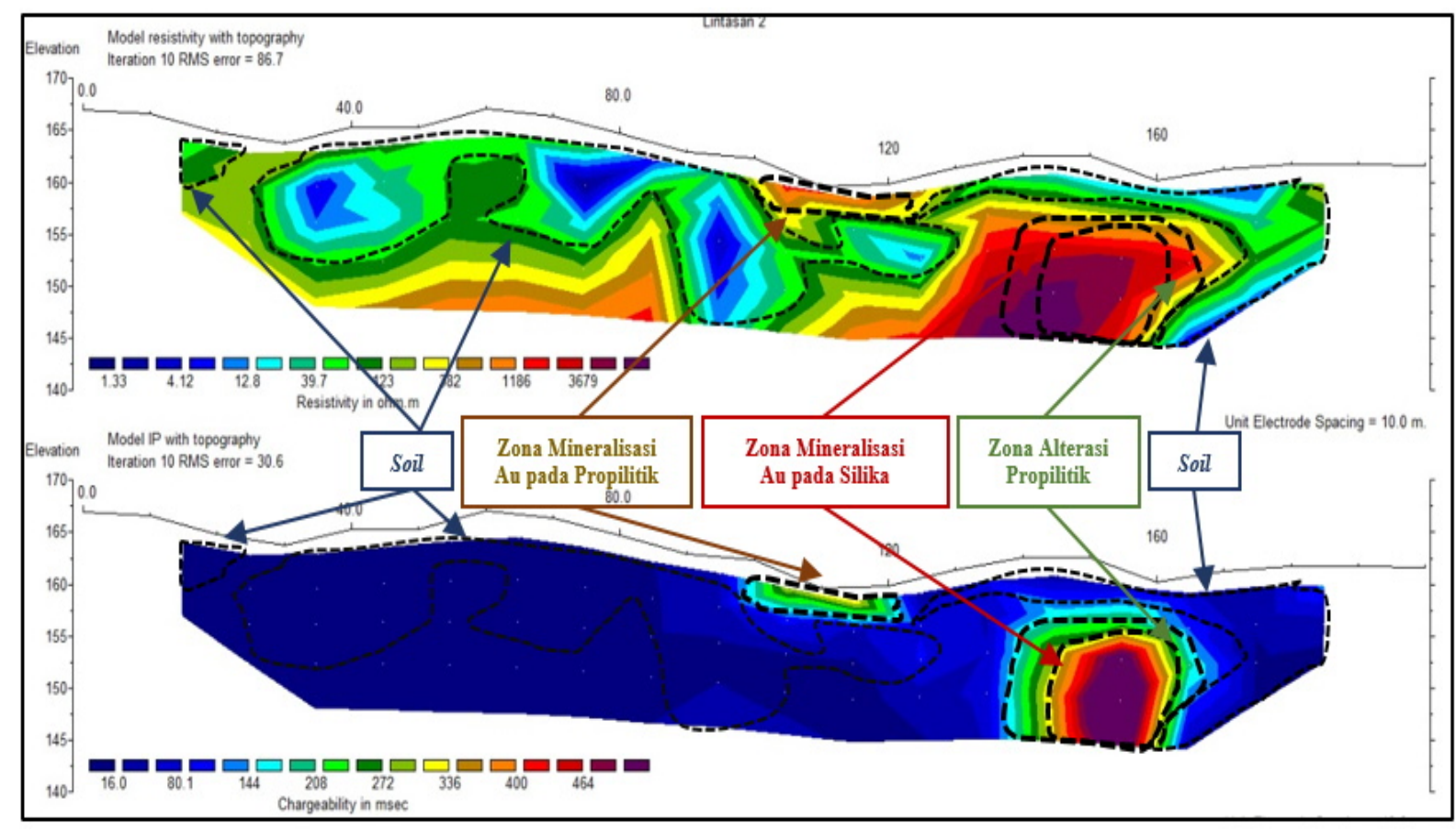

Gambar 7. Penampang resistivitas dan chargeabilitas lintasan 2.

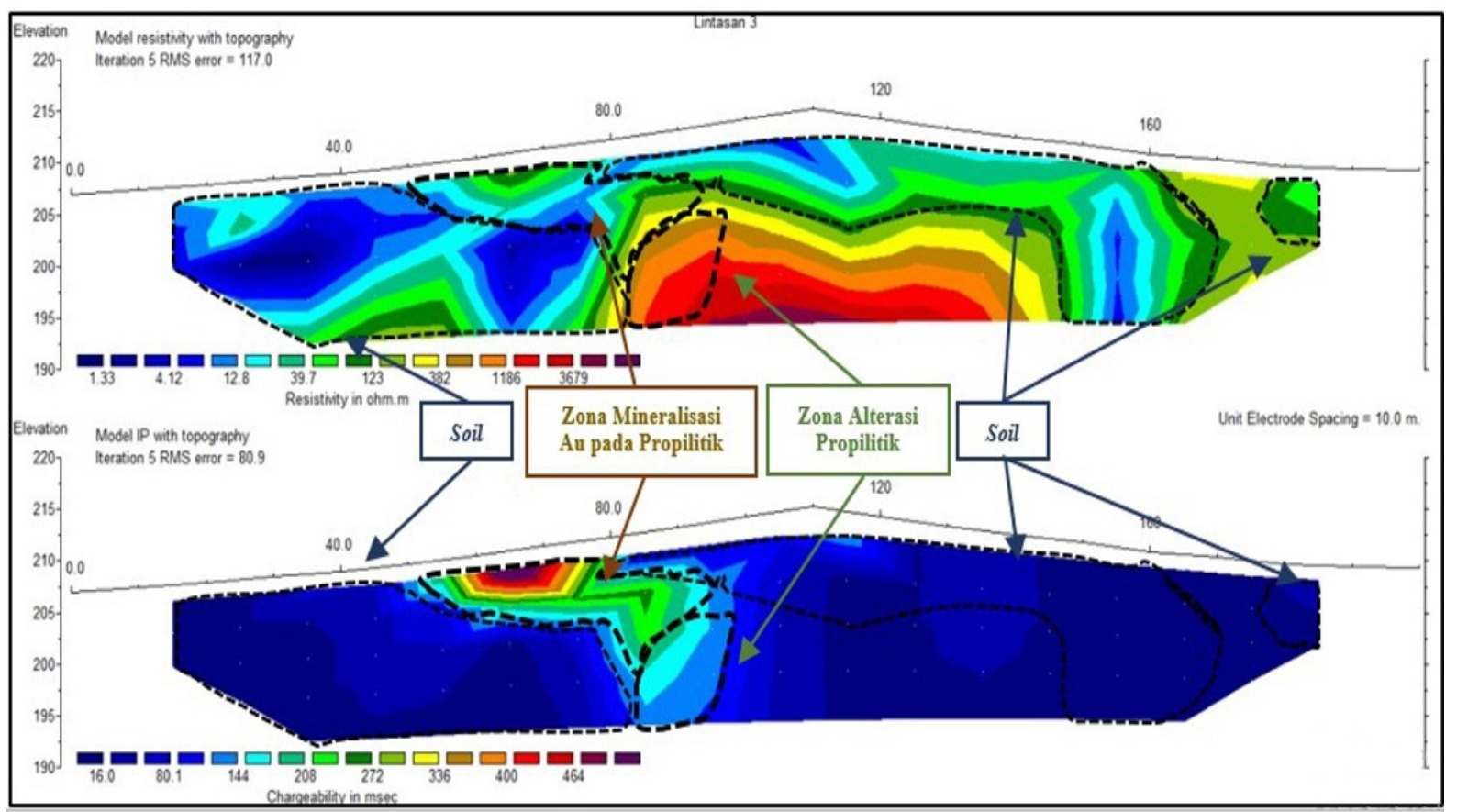

Gambar 8. Penampang resistivitas dan chargeabilitas lintasan 3. 


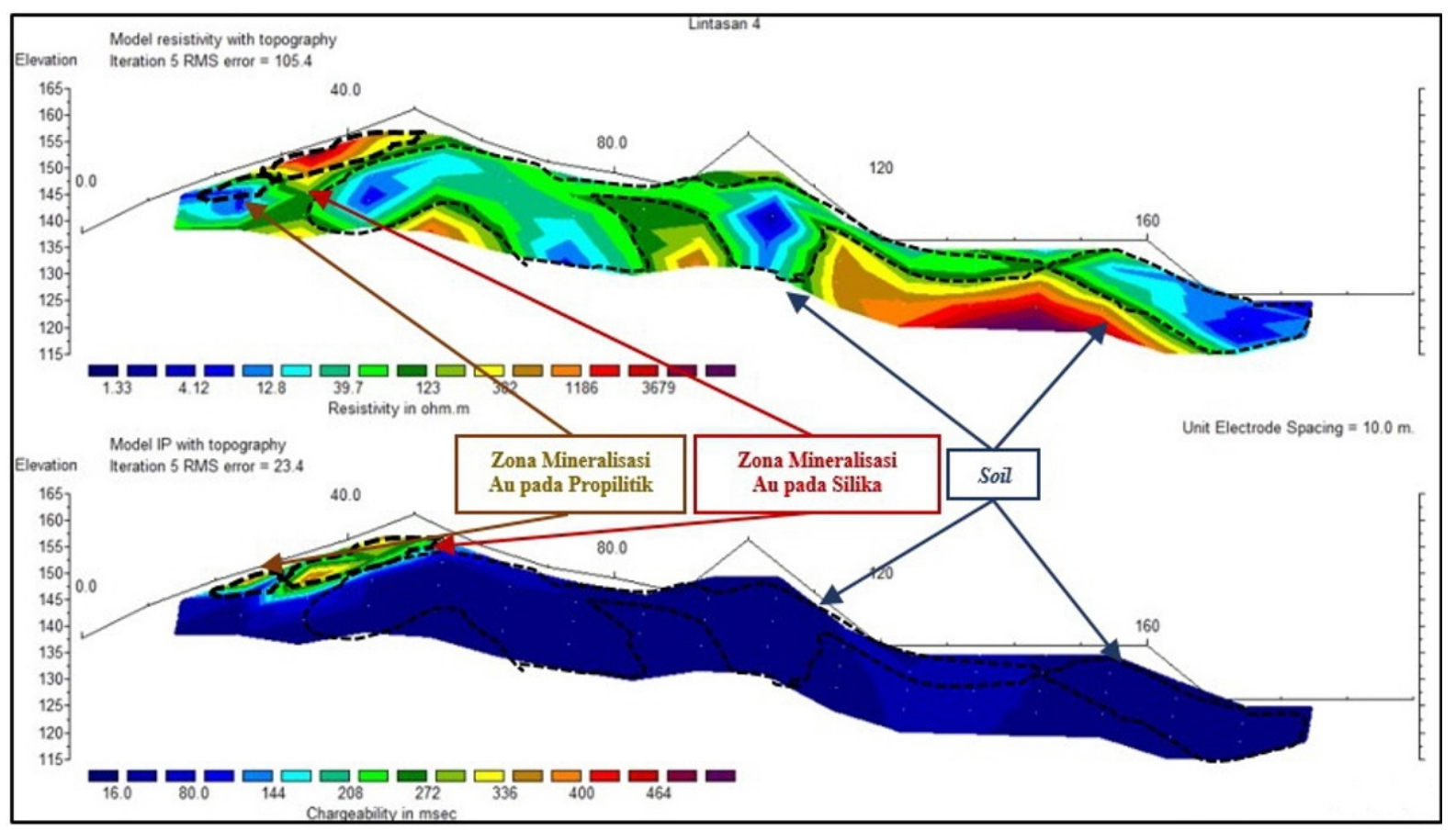

Gambar 9. Penampang resistivitas dan chargeabilitas lintasan 4.

Keberadaan zona mineralisasi juga ditemukan pada panjang lintasan 15-20 meter dengan elevasi 150-155 dimana zona mineralisasi tersebut berasosiasi pada propilitik yang ditunjukkan dengan nilai resistivitas sedang yaitu $100-700 \Omega \mathrm{m}$ dan nilai chargeabilitas yang sedang-tinggi yaitu $\geq 100$ ms.

Selain keberadaan mineralisasi pada lintasan 1 ditemukan pula zona alterasi pada panjang lintasan 70-90 meter dengan elevasi 135-150 meter dimana zona alterasi tersebut merupakan alterasi propilitik yang ditunjukkan dengan nilai resistivitas yang tinggi yaitu $>700 \Omega \mathrm{m}$ dan nilai chargeabilitas yang sedang yaitu 100-300 ms.

Selain itu soil atau lapisan jenuh air dapat terlihat pada panjang lintasan 20-75 meter dengan elevasi 145-155 meter serta pada panjang lintasan 115-185 meter dengan elevasi 127.5-147.5 meter yang ditunjukkan dengan nilai resistivitas yang rendah yaitu $0-100 \Omega \mathrm{m}$ dan nilai chargeabilitas yang rendah pula yaitu 0-100 ms.

Dari hasil penampang 2D resistivitas dan chageabilitas pada lintasan 1 dimana target penelitian ditemukan bahwa zona mineralisasi berada pada batuan beku diabas yang mempunyai respon nilai resistivitas yang tinggi yaitu $>700 \Omega \mathrm{m}$ dan nilai chargeabilitas yang rendah yaitu 0-100 ms.

Batuan beku diabas tersebut menjadi host rock mineral-mineral logam seperti pirit, serisit dan sebagainya yang terdisemenisasi serta merupakan mineralisasi penciri endapan mineral $(A u)$. 


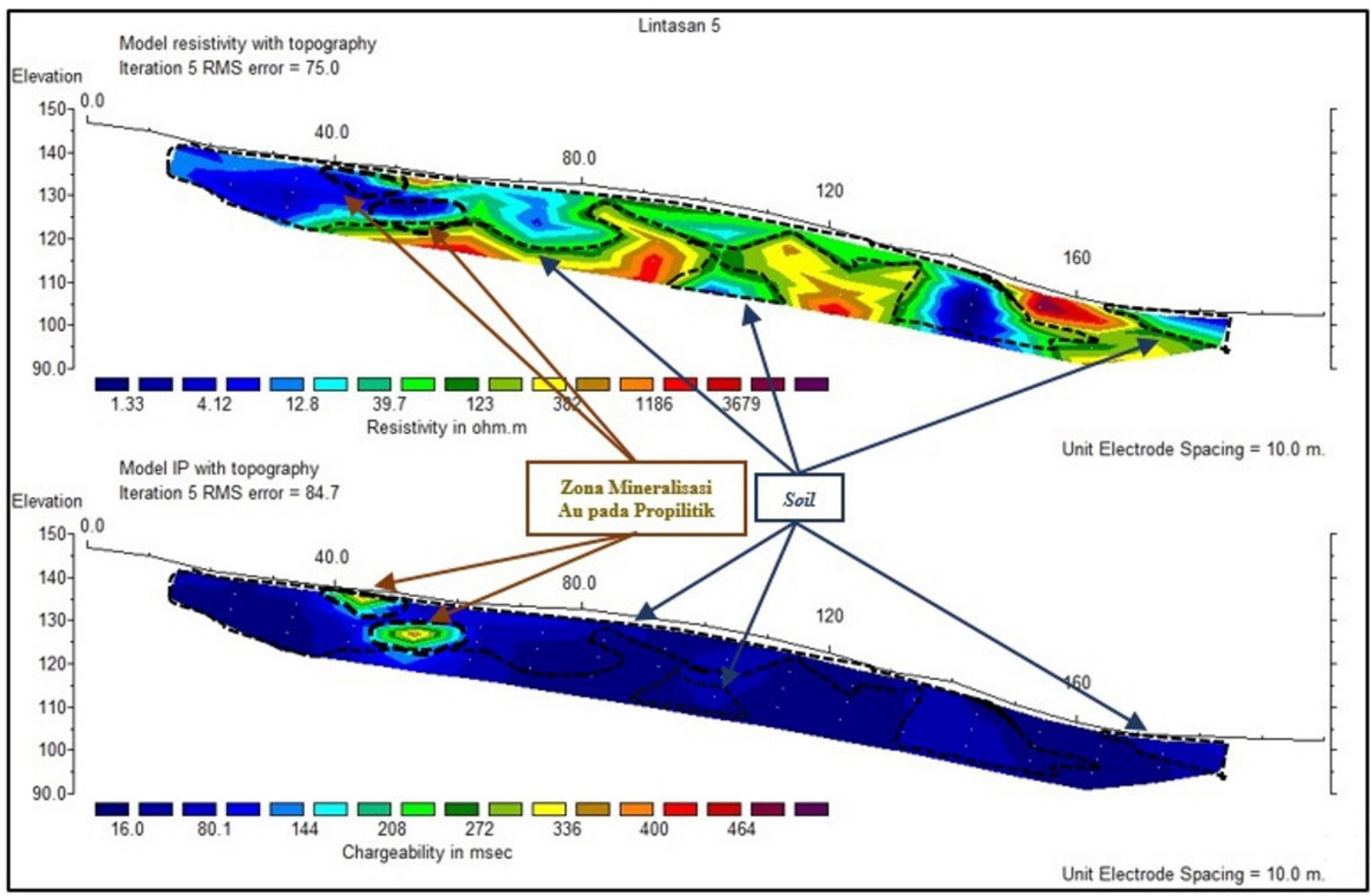

Gambar 10. Penampang resistivitas dan chargeabilitas lintasan 5.

Dari lintasan 1, 2, 3, 4, dan 5 (Gambar 6 hingga 10) semua menunjukkan zona mineralisasi $\mathrm{Au}$, akan tetapi pada lintasan 3 dan 5 keberadaan zona mineralisasi menunjukkan nilai yang tidak begitu tinggi karena adanya pengaruh alterasi propilitik. Dari hasil korelasi penampang chargeabilitas (Gambar 11) potensi keberadaan endapan mineral menunjukkan orientasi arah utaraselatan.

Berdasarkan pemodelan 3D (Gambar 12) diketahui bahwa zona mineralisasi Au diperkirakan mempunyai volume sebesar $70,500 \mathrm{~m}^{3}$. Volume tersebut didapat dari perhitungan cut off berdasarkan nilai chargeabilitas sebelumnya yaitu $>300 \mathrm{~ms}$.

\section{KESIMPULAN}

Berdasarkan hasil analisis penelitian di Daerah Karangsambung dapat diambil beberapa kesimpulan, antara lain: a. Keberadaan zona mineralisasi pada silika urat kuarsa yang berkembang berupa vein menunjukkan adanya struktur (kekar) ditunjukkan dengan nilai resistivitas dan chargeabilitas yang tinggi yaitu $>700 \Omega \mathrm{m}$ dan $>300 \mathrm{~ms}$.

b. Lokasi yang terindikasi keterdapatan mineralisasi Au yaitu pada lintasan 1, 2, dan 4 dengan potensi persebaran endapan mineral yang memanjang arah utaraselatan.

c. Potensi volume persebaran zona mineralisasi $\mathrm{Au}$ yaitu berkisar sebesar $70,500 \mathrm{~m}^{3}$.

Untuk mengembangkan penelitian ini agar lebih baik maka diperlukan beberapa saran seperti dilakukan pemboran eksplorasi guna mengetahui secara pasti litologi di bawah permukaan dan menjadi data ikat interpretasi geolistrik. 


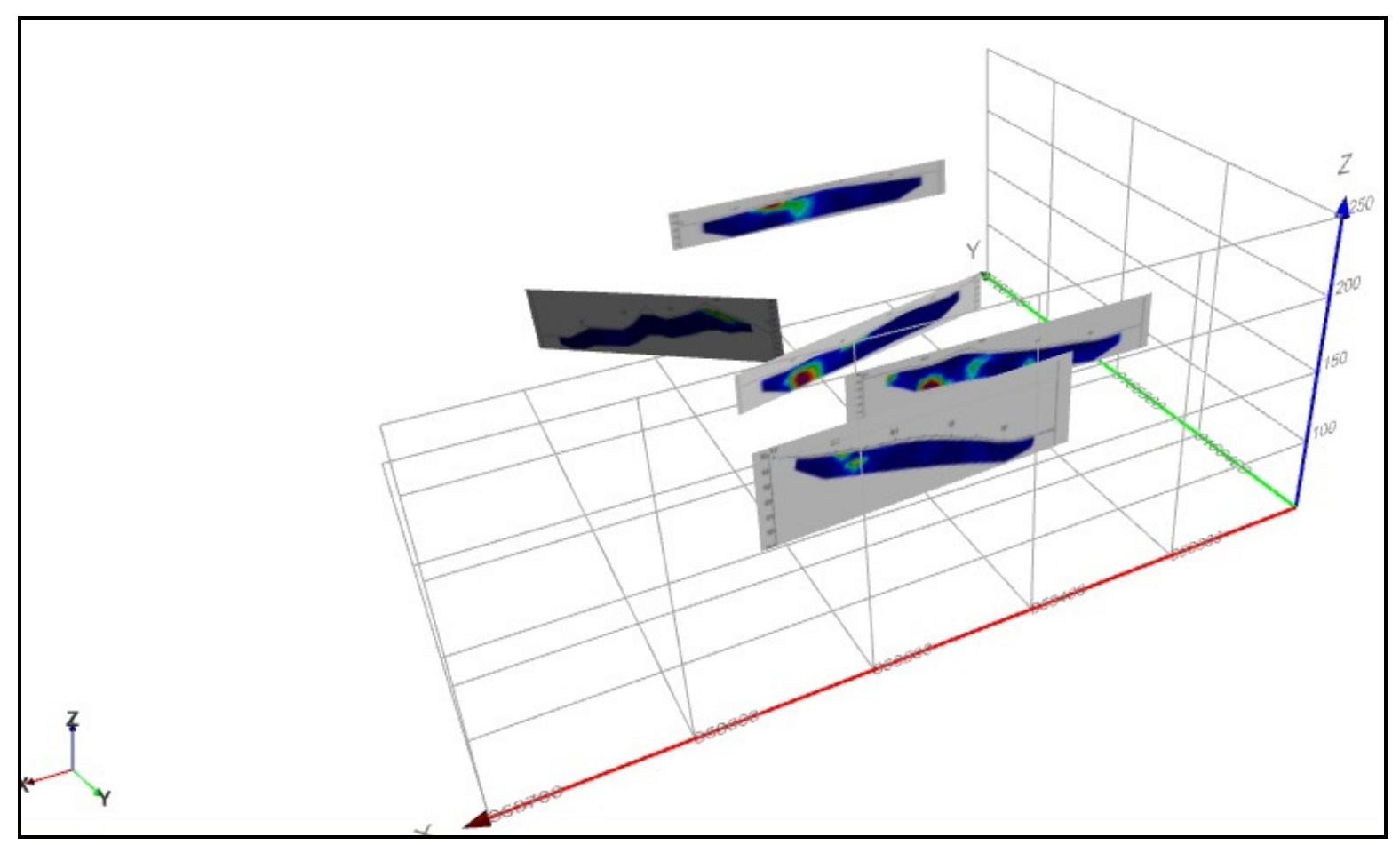

Gambar 11. Korelasi penampang chargeabilitas.

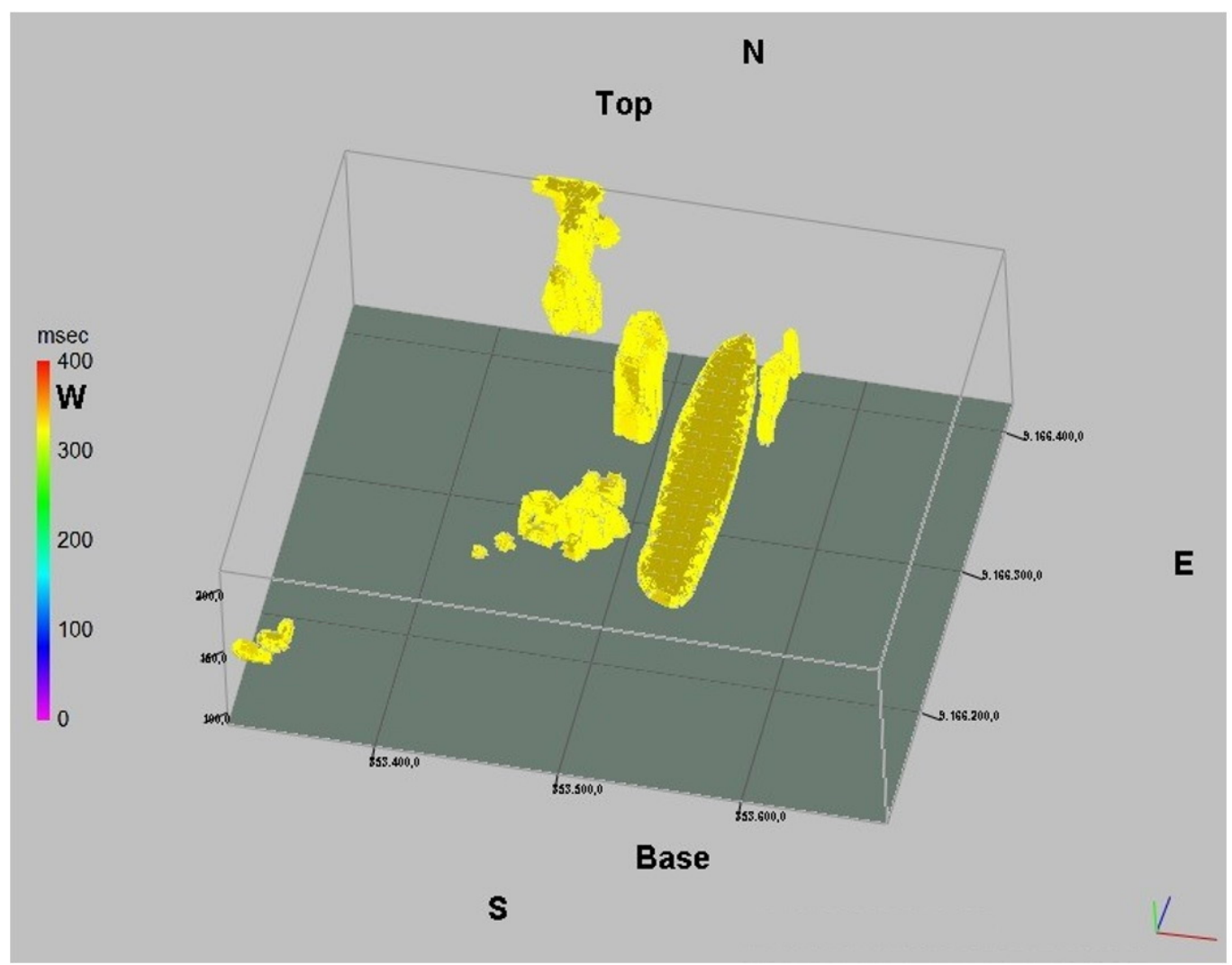

Gambar 12. Pemodelan 3D nilai chargeabilitas. 


\section{UCAPAN TERIMA KASIH}

Penulis mengucapkan terima kasih sebesarbesarnya kepada Teknik Geofisika 2015 (MAGNETO) UPN "Veteran" Yogyakarta yang telah melakukan proses akuisisi dan menyediakan data untuk melakukan penelitian ini.

\section{DAFTAR PUST AKA}

Ali, M., Sun, S., Qian, W ., Bohari, A. D., Claire, D., Faruwa, A. R., \& Zhang, Y. (2020). Borehole resistivity and induced polarization tomography at the Canadian Shield for Mineral Exploration in north-western Sudbury. E3S Web of Conferences, 168. https://doi.org/10.1051/e3sconf/20201680000 2

Asikin, S., Handoyo, A., Busono, H., \& Gafoer, S. (1992). Geologic Map of Kebumen Quadrangle, Java, Scale 1: 100.000.

Corbett, G. J., \& Leach, T. M. (1998). Southwest Pacific Rim Gold-Copper Systems: Structure, Alteration, and Mineralization. Society of Economic Geologists. https://doi.org/10.5382/SP.06

Dakir, I., Benamara, A., Aassoumi, H., Ouallali, A., $\&$ Ait Bahammou, Y. (2019). A pplication of Induced Polarization and Resistivity to the Determination of the Location of Metalliferous Veins in the Taroucht and Tabesbaste Areas (Eastern Anti-Atlas, Morocco). International Journal of Geophysics, 2019. https://doi.org/10.1155/2019/5849019

Gary, M., McAfee, R., \& Wolf, C. L. (1972). Glossary of Geology. American Geological Institute.

Irvine, R. J., \& Smith, M. J. (1990). Geophysical Exploration For Epithermal Gold Deposits. Elsivier Science Publisher.

Lowrie, W. (2007). Fundamental of Geophysics, 2nd. Cambridge U niversity.
Lucas, J. M. (1985). Gold M ineral Facts and Problems. United State Dept of the Interior. Burreau of M ines Preprint from Bulletin, 675, 1-6.

M ostafaei, K., \& Ramazi, H. (2019). Investigating the applicability of induced polarization method in ore modelling and drilling optimization: a case study from Abassabad, I ran. Near Surface Geophysics, 17(6), 637-652. https://doi.org/https://doi.org/10.1002/nsg.12 055

Noor, D. (2009). Pengantar Geologi. CV. Graha IImu. Pakuan U niversity Press.

Puswanto, E., \& Ansori, C. (2011). Karakteristik Urat Kuarsa Epitermal Pada Batuan Induk Teralterasi Formasi Kompleks Melange Luk Ulo Di Kecamatan Sadang, Kabupaten Kebumen. PROSIDING Pemaparan Hasil Penelitian Puslit Geoteknologi, 15-20.

Reynold, J. M. F. (2011). An Introduction to A pplied and Environmental Geophysics. W illey.

Srigutomo, W., Trimadona, \& Pratomo, P. M. (2016). 2D Resistivity and Induced Polarization Measurement for $M$ anganese Ore Exploration. Journal of Physics: Conference Series, 739(1). https://doi.org/10.1088/17426596/739/1/012138

Telford, W. M., Geldart, L. P., Sheriff, R. E., \& Keys, D. A. (1976). Applied Geophysics, Edisi 1. Cambridge U niversity Press.

Zhdanov, M., Endo, M., Cox, L., \& Sunwall, D. (2018). Effective-medium inversion of induced polarization data for mineral exploration and mineral discrimination: Case study for the copper deposit in Mongolia. Minerals, 8(2). https://doi.org/10.3390/min8020068 